\title{
Spatial Learning of Mice Lacking a Neuron-Specific Epidermal Growth Factor Family Protein, NELL2
}

\author{
Shogo Matsuyama ${ }^{1, \uparrow}$, Nobutaka Doe ${ }^{2, \uparrow}$, Naoki Kurihara ${ }^{3}$, Katsuyuki Tanizawa ${ }^{4}$, Shun'ichi Kuroda ${ }^{4}$, \\ Hiroyuki Iso ${ }^{5}$, and Masato Horie ${ }^{3, *}$ \\ ${ }^{1}$ Division of Molecular Pharmacology and Pharmacogenomics, Department of Genome Sciences, \\ Kobe University Graduate School of Medicine, Hyogo 650-0017, Japan \\ ${ }^{2}$ Department of Integrated Psychological Science, Kwansei Gakuin University, Hyogo 662-8501, Japan \\ ${ }^{3}$ Second Institute of New Drug Discovery, Otsuka Pharmaceutical Co., Ltd., Tokushima 771-0192, Japan \\ ${ }^{4}$ Department of Structural Molecular Biology, Institute of Scientific and Industrial Research, Osaka University, \\ Osaka 567-0047, Japan \\ ${ }^{5}$ Department of Behavior Science, Hyogo College of Medicine, Hyogo 663-8501, Japan
}

Received February 22, 2005; Accepted May 1, 2005

\begin{abstract}
NELL2 is a neuron-specific thrombospondin-1-like extracellular protein containing six epidermal growth factor-like domains. We previously disrupted the NELL2 gene in mice by gene targeting and showed that long-term potentiation is enhanced in vivo in the dentate gyrus of NELL2-deficient mice. To further elucidate the physiological roles of NELL2, we performed a behavioral characterization of $N E L L 2^{-/-}$and their heterozygous control mice. NELL2-deficient mice exhibited learning impairment in the Morris water maze task. However, we observed no difference in passive avoidance learning between $N E L L 2^{-/-}$and $N E L L 2^{+/-}$mice. These observations suggest that NELL2 plays an important role in hippocampus-dependent spatial learning and that emotional learning does not depend critically on NELL2.
\end{abstract}

Keywords: NELL2, epidermal growth factor, thrombospondin, hippocampus, spatial learning

\section{Introduction}

The nel gene has been identified as a gene encoding a protein containing six epidermal growth factor (EGF)like domains from a chick embryo-derived cDNA library (1). The nel mRNA is ubiquitously expressed in chick embryos, but after hatching, it is retained only in neural tissues (1). The NELL1 and NELL2 genes were first isolated from a human fetal brain cDNA library as a part of the Human Genome Project (2) and then isolated from a rat brain cDNA library as genes coding for protein kinase C-interacting proteins (3). The NELL2 gene is more closely related to the nel gene than NELL1 and is expressed predominantly in the brain (2). Expression of both the NELL2 mRNA (3) and its encoding protein (4) is highest in the hippocampus, which is a center for spatial learning.

\footnotetext{
These authors contributed equally to this work.

*Corresponding author. FAX: +81-88-665-6106

E-mail: mhorie@research.otsuka.co.jp
}

The NELL2 protein is a heparin-binding protein and shares several domains ( $\mathrm{N}$-terminal globular domain, von Willebrand factor $\mathrm{C}$ domain, and EGF-like domain) with thrombospondin (TSP)-1 (3). Mitogen-activated protein kinase (MAPK) family members, including extracellular signal-regulated kinase (ERK) and c-Jun $\mathrm{N}$-terminal kinase (JNK), respond to various extracellular stimuli, thereby integrating a signal into the nucleus (5). ERK and JNK have been implicated in mediating TSP-1-induced signal transduction in T-cells (6) and capillary endothelial cells (7). In addition to the shared domain structure of NELL2 with TSP-1, we have previously shown that NELL2 promotes survival of rat primary cultured neurons through activation and suppression of JNK and ERK, respectively (8). It has been reported that ERK is required for the induction of hippocampal LTP (9), whereas JNK appears to be inhibitory on LTP (10). These observations suggest that NELL2 may play a role in synaptic plasticity. To assess the role of NELL2 in LTP induction, we generated NELL2-deficient mice by gene targeting, and found 
that production of LTP at perforant path-granule cell synapses was significantly larger in NELL2-deficient mice (11). Thus, we speculated that NELL2-deficient mice might perform better in hippocampus-dependent learning paradigms. To elucidate the role of NELL2 in learning and memory, we investigated memory function of these mice in the Morris water maze and passive avoidance paradigms.

\section{Materials and Methods}

\section{Behavioral tests in NELL2-deficient mice}

Generation of NELL2 mutant mice has been described previously (11). An original chimeric stock shared a mixed 129/Sv and C57BL/6 genome (11). NELL2 mutant mice were backcrossed to $\mathrm{C} 57 \mathrm{BL} / 6$ mice for eight generations before behavioral analysis. All experiments were conducted in accordance with the National Institute of Health guide "Principles of Laboratory Animal Care (NIH publication No.85-23, revised 1985)"; and the care and use of animals adhered to the "Guide for the Care and Use of Laboratory Animals of the Department of Integrated Psychological Science, Kwansei Gakuin University". Phenotypic behavioral differences between NELL2 $2^{-/-}$and $N E L L 2^{+/-}$mice were assessed with a specific behavioral test battery consisting of open field activity, water maze learning, and passive avoidance learning. These tests were run in listed order with 11-week-old male mice $\left(N E L L 2^{-/-}\right.$ mice, $\mathrm{n}=10 ; N E L L 2^{+/-}$mice, $\left.\mathrm{n}=10\right)$. An analysis of variance (ANOVA), with genotype $\left(N E L L 2^{-/-}\right.$vs $N E L L 2^{+/-}$) as the between-subject factor and repeated measure such as period or day as the within-subject factor, was conducted on the data in each test. When necessary, data were analyzed using the $t$-test and oneway ANOVA and subsequent Fisher's least-squares difference (LSD) test. In all statistical analyses, the level of significance was set at $P<0.05$.

\section{Open-field activity}

A transparent acrylic box $(30 \times 30 \times 30 \mathrm{~cm})$ housed in a ventilated sound-attenuating shell was used. In the light condition, an overhead incandescent bulb provided room lighting that measured approximately $110 \mathrm{~lx}$ inside the open-field arena. In addition, a fan attached in the upper part of the wall at one end of the shell presented a masking noise of $45 \mathrm{~dB}$. On each $\mathrm{X}$ and $\mathrm{Y}$ bank of the open-field, two infrared beams were attached $2 \mathrm{~cm}$ above the floor in $10-\mathrm{cm}$ interval making a flip-flop circuit between two beams. Total number of circuit breaks was counted as the locomotor activity. On the $\mathrm{X}$ bank, 12 infrared beams were attached $4.5 \mathrm{~cm}$ above the floor in $2.6-\mathrm{cm}$ interval, and the total number of beam crossings was counted as the rearing activity. Animals were allowed to explore freely in the open-field arena for $20 \mathrm{~min}$. The first half of the session was a light period, and the latter half was a dark period.

\section{Water maze learning}

Morris water maze learning task (12) adapted for mice was conducted to assess spatial learning ability. The apparatus consisted of a circular pool $(36 \mathrm{~cm}$ high $\times 90 \mathrm{~cm}$ diameter) filled with water maintained at $21 \pm 1^{\circ} \mathrm{C}$ and made opaque by adding nontoxic black paint. A platform (11-cm diameter) was situated in the north quadrant of the pool. It was submerged $5 \mathrm{~mm}$ below the water level in case of maze training (Day $2-4$ ) and appeared upon the surface of the water in the case of visible training (Day 1). Five trials per day were conducted for 4 successive days. Latency to reach the platform was recorded. After the 4th day of training, a 60 -s probe trial was conducted. The platform was removed, and each mouse was placed into the south quadrant of the pool. Time spent in each quadrant was recorded during the probe trial.

\section{Passive avoidance learning}

Animals were trained in a step-through type passive avoidance apparatus consisting of two compartments, one light $(10 \times 10 \times 20 \mathrm{~cm})$ and one dark $(10 \times 10 \times$ $20 \mathrm{~cm}$ ), with a grid floor. A guillotine door separated the two compartments. In the acquisition trial, mice were individually placed in the light compartment. Five seconds later, the door to the dark compartment was opened. When the mouse moved into the dark compartment, the guillotine door was closed, and 10 and $18 \mathrm{~s}$ later, a scrambled electrical shock $(0.36 \mathrm{~mA}, 3 \mathrm{~s})$ was delivered through the grid floor by a shock generator. Twenty-four hours later, the retention test without shock was conducted. Each mouse was placed in the light compartment and the latency to enter the dark compartment was recorded up to a maximum of $180 \mathrm{~s}$.

\section{Results}

\section{Normal locomotor activity}

$N E L L 2^{--}$and their heterozygous control mice did not differ in their activity as assessed by locomotion and rearing scores in the open-field test (Fig. 1). A 2 (genotype) $\times 2$ (period: light $v s$ dark) ANOVA applied to the data of each index of activity supported the notion that there were no significant main effect of genotype and interaction of genotype $\times$ period $\left[F_{\mathbf{S}}<1\right]$. These suggest that there is no difference in basic motor function and emotionality between $N E L L 2^{-/-}$and $N E L L 2^{+/-}$ mice. 

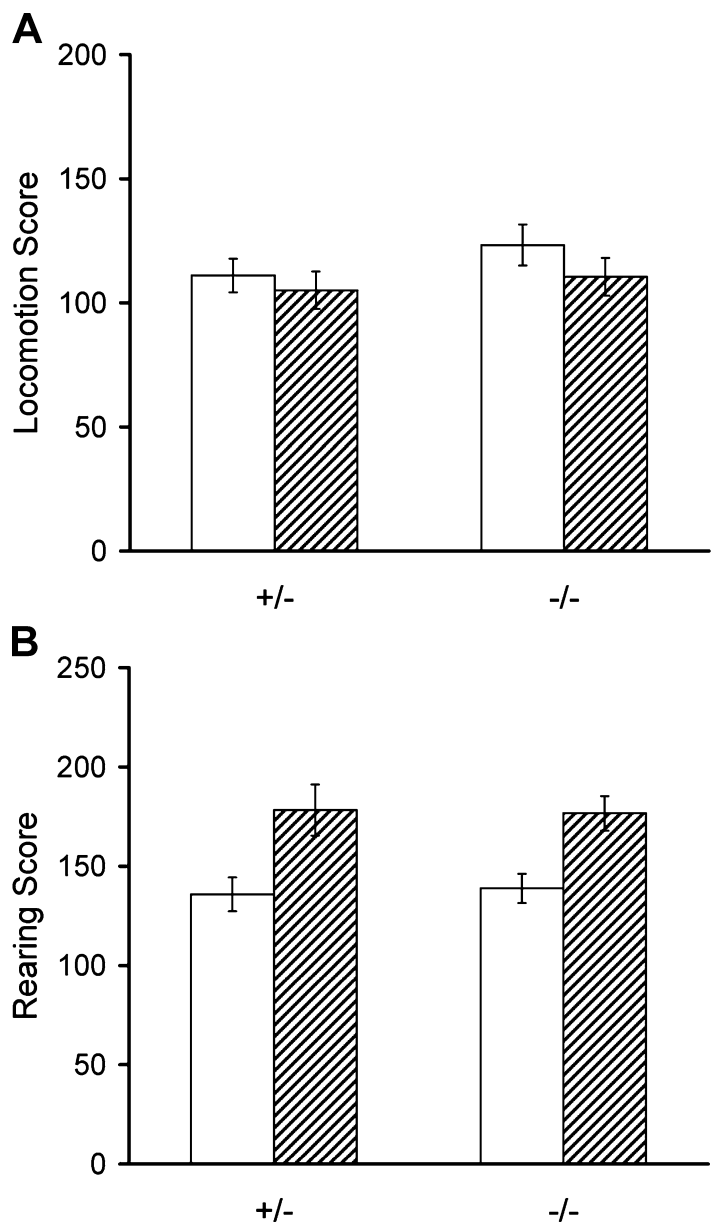

Fig. 1. Normal locomotor activity of NELL2-deficient mice in the open field test. Both locomotor (A) and rearing (B) activities of $N E L L 2^{+/-}(\mathrm{n}=10)$ and NELL2 ${ }^{-/-}(\mathrm{n}=10)$ mice are expressed by the number of infrared beam breaks. In the 20 -min observation period, the first half of the session was a light period (open bar), and the latter half was a dark period (hatched bar). Data are given as means \pm S.E.M.

\section{Impaired spatial learning}

Since hippocampal LTP is enhanced in NELL2deficient mice (11), we examined the spatial learning ability of these mice. NELL2 homozygous and heterozygous mutants were subjected to the Morris water maze task. There was no group difference in the first trial of day 1 (visible training) $[t<1]$ (the averages of $N E L L 2^{-/-}$ and $N E L L 2^{+/-}$mice, respectively, were 52.9 and $50.4 \mathrm{~s}$ ). This implies that there is no difference in swimming skill between $N E L L 2^{-/-}$and $N E L L 2^{+/-}$mice. Both groups of mice decreased their escape latencies over 4 days of training (Fig. 2A). However, NELL2 $2^{-/-}$mice were found to take significantly longer to locate the hidden platform than $N E L L 2^{+/-}$mice $[F(1,18)=7.97, P<0.05]$. In the subsequent probe test, $N E L L 2^{+-}$mice spent significantly more time in the target quadrant than in the others
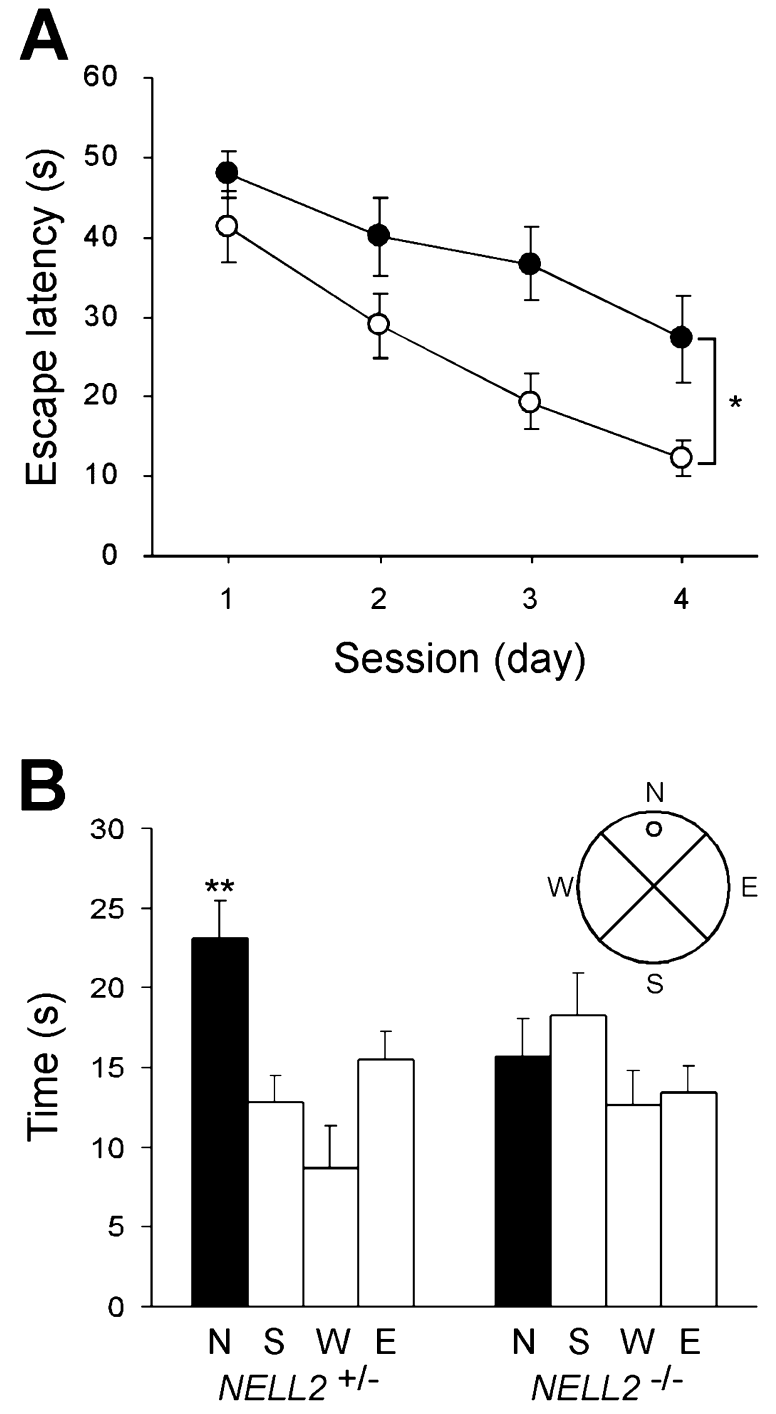

Fig. 2. Spatial learning impairment of NELL2-deficient mice in the Morris water maze task. A: Escape latencies (mean \pm S.E.M.) of $N E L L 2^{-/-}$(closed circle; $\left.\mathrm{n}=10\right)$ and $N E L L 2^{+-}$(open circle; $\left.\mathrm{n}=10\right)$ mice. The effect of genotype was significant $\left({ }^{*} P<0.05\right)$. B: The probe test after all the training sessions. Times (mean \pm S.E.M.) spent in each quadrant of the water pool are shown. $\mathrm{N}$ (north) is the target quadrant (closed bar). $N E L L 2^{+/-}$mice spent significantly more time in the $\mathrm{N}$ than in the other three quadrants (open bars) $(* * P<0.05)$, while $N E L L 2^{-/-}$mice did not.

$[F(3,27)=5.72, P<0.01$, one-way ANOVA followed by Fisher's LSD test], whereas $N E L L 2^{-/-}$mice did not $[F<1]$ (Fig. 2B). The data indicate an impairment of the spatial learning ability in NELL2-deficient mice.

\section{Normal passive avoidance learning}

To assay another type of learning and memory of NELL2-deficient mice, we used a step-through passive avoidance paradigm. Both $N E L L 2^{-/-}$and $N E L L 2^{+/-}$mice showed longer latency in the retention test trial than in the acquisition trial (Fig. 3). A 2 (genotype) $\times 2$ (trial) 


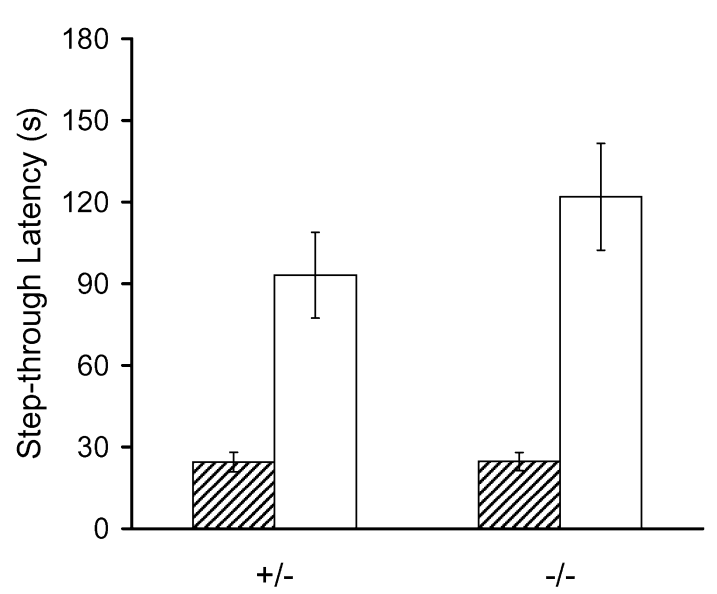

Fig. 3. Intact performance of NELL2-deficient mice in the passive avoidance task. The retention trial was done $24 \mathrm{~h}$ after the acquisition trial. Latency to enter the dark compartment of the chamber in the retention test trials (open bar) was significantly longer than that in the acquisition trials (hatched bar) for $N E L L 2^{+/}(\mathrm{n}=10)$ and $N E L L 2^{-/-}$ $(\mathrm{n}=10)$ mice. Data are given as means \pm S.E.M.

ANOVA yielded no significant main effect of genotype $[F(1,18)=1.22]$ and the interaction of genotype $\times$ trial $[F(1,18)=1.31]$, but the main effect of trial was significant $[F(1,18)=44.01, P<0.001]$. Thus, the presence or absence of NELL2 does not affect the acquisition and retention of memory in the passive avoidance task.

\section{Discussion}

We studied the role of NELL2 in learning and memory using the mutant mouse approach. Although LTP in vivo in the dentate gyrus is enhanced in NELL2deficient mice (11), the learning ability of these mice is impaired as assessed by the Morris water maze hidden platform task. The probe test also indicated the impaired spatial learning ability of NELL2-deficient mice. Since the water maze performance of $N E L L 2^{+/-}$mice is similar to that of C57BL/6 mice (our unpublished observation), a loss of both NELL2 alleles seems to be required for impairment of spatial learning. Modification of the threshold for synaptic plasticity in response to prior activity is a characteristic feature of the hippocampus, and release of an LTP-inhibiting factor in response to strong stimulation has been suggested (13). Heparinbinding growth associated molecule (HB-GAM) has been proposed as a candidate for such suppressor of LTP (14). Hippocampal LTP is enhanced in HB-GAMdeficient mice (15). HB-GAM contains two $\beta$-sheet structures that are homologous with the TSP type 1 repeat. It has been reported that HG-GAM-deficient mice also show spatial learning impairment (16). It is noteworthy that mice lacking two different heparin- binding proteins sharing homology to TSP (i.e., HB-GAM and NELL2) exhibit enhanced LTP in the hippocampus and reduced learning ability in the water maze task.

LTP is the major cellular model of the mechanisms underlying activity-dependent plasticity in the hippocampus (17), and it is often correlated with spatial learning and memory $(18-20)$. However, several reports have shown that increased LTP in mutant mice are associated with impaired learning or memory (16, $21-23)$. Moreover, it has been shown that saturation of LTP results in spatial learning impairment (24). It is also reported that induction of LTP after learning disrupts retention of spatial memory (25). Thus, it seems that the abnormality of hippocampal physiology, either excessive or short of function, could lead to detrimental results in learning and memory that need integrated action of the hippocampus.

Nelson etal. (26) recently reported that NELL2 promotes differentiation of motor and sensory neurons and stimulates mitogenesis of dorsal root ganglia in chickens. We also found that NELL2 signals through ERK and JNK to promote survival of primary cultured neurons from fetal rat brain (8). Although the hippocampal structure of NELL2-deficient mice is grossly normal (our unpublished observation), NELL2 deficiency might alter differentiation and/or signal transduction properties of hippocampal neurons, which, in turn, leads to spatial memory impairment and enhanced LTP response (11).

Although behavioral characterization of wild-type mice will be needed to further strengthen our findings, this study clearly pointed out that NELL2 plays an important role in spatial learning. Identification of receptor(s) of this EGF family protein should provide further insight into the complex regulatory processes involved in LTP and memory function. Our present study of NELL2 should contribute to a growing understanding of the function of TSP-like proteins in the central nervous system.

\section{Acknowledgments}

We acknowledge Drs. Akira Matsumoto and Naoaki Saito for helpful discussions and comments on the manuscript. This work was supported in part by a Grant-in-Aid for Scientific Research on Exploratory Research from the Ministry of Education, Culture, Sports, Science, and Technology of Japan (S.K., No. 13878161 and 15300126). 


\section{References}

1 Matsuhashi S, Noji S, Koyama E, Myokai F, Ohuchi H, Taniguchi S, et al. New gene, nel, encoding a M(r) $93 \mathrm{~K}$ protein with EGF-like repeats is strongly expressed in neural tissues of early stage chick embryos. Dev Dyn. 1995;203:212-222.

2 Watanabe TK, Katagiri T, Suzuki M, Shimizu F, Fujiwara T, Kanemoto N, et al. Cloning and characterization of two novel human cDNAs (NELL1 and NELL2) encoding proteins with six EGF-like repeats. Genomics. 1996;38:273-276.

3 Kuroda S, Oyasu M, Kawakami M, Kanayama N, Tanizawa K, Saito $\mathrm{N}$, et al. Biochemical characterization and expression analysis of neural thrombospondin-1-like proteins NELL1 and NELL2. Biochem Biophys Res Commun. 1999;265:79-86.

4 Oyasu M, Kuroda S, Nakashita M, Fujimiya M, Kikkawa U, Saito N. Immunocytochemical localization of a neuron-specific thrombospondin-1-like protein, NELL2: light and electron microscopic studies in the rat brain. Mol Brain Res. 2000;76: $151-160$.

5 Chang L, Karin M. Mammalian MAP kinase signalling cascades. Nature. 2001;410:37-40.

6 Wilson KE, Li Z, Kara M, Gardner KL, Roberts DD. Beta 1 integrin- and proteoglycan-mediated stimulation of $\mathrm{T}$ lymphoma cell adhesion and mitogen-activated protein kinase signaling by thrombospondin-1 and thrombospondin-1 peptides. J Immunol. 1999; 163:3621-3628.

7 Jimenez B, Volpert OV, Reiher F, Chang L, Munoz A, Karin M, et al. c-Jun N-terminal kinase activation is required for the inhibition of neovascularization by thrombospondin-1. Oncogene. 2001;20:3443-3448.

8 Aihara K, Kuroda S, Kanayama N, Matsuyama S, Tanizawa K, Horie M. A neuron-specific EGF family protein, NELL2, promotes survival of neurons through mitogen-activated protein kinases. Mol Brain Res. 2003;116:86-93.

9 Rosenblum K, Futter M, Voss K, Erent M, Skehel PA, French P, et al. The role of extracellular regulated kinases I/II in late-phase long-term potentiation. J Neurosci. 2002;22:5432-5441.

10 Vereker E, O’Donnell E, Lynch MA. The inhibitory effect of interleukin-1beta on long-term potentiation is coupled with increased activity of stress-activated protein kinases. J Neurosci. 2000;20:6811-6819.

11 Matsuyama S, Aihara K, Nishino N, Takeda S, Tanizawa K, Kuroda $\mathrm{S}$, et al. Enhanced long-term potentiation in vivo in dentate gyrus of NELL2-deficient mice. Neuroreport. 2004;15: 417-420.

12 Morris RG, Garrud P, Rawlins JN, O'Keefe J. Place navigation impaired in rats with hippocampal lesions. Nature. 1982;297: 681-683.

13 Kauer JA. Blockade of hippocampal long-term potentiation by sustained tetanic stimulation near the recording site. J Neurophysiol. 1999;81:940-944.

14 Lauri SE, Rauvala H, Kaila K, Taira T. Effect of heparin-binding growth-associated molecule (HB-GAM) on synaptic transmission and early LTP in rat hippocampal slices. Eur J Neurosci. 1998;10:188-194.

15 Amet LE, Lauri SE, Hienola A, Croll SD, Lu Y, Levorse JM, et al. Enhanced hippocampal long-term potentiation in mice lacking heparin-binding growth-associated molecule. Mol Cell Neurosci. 2001;17:1014-1024.

16 Pavlov I, Voikar V, Kaksonen M, Lauri SE, Hienola A, Taira T, et al. Role of heparin-binding growth-associated molecule (HB-GAM) in hippocampal LTP and spatial learning revealed by studies on overexpressing and knockout mice. Mol Cell Neurosci. 2002;20:330-342.

17 Bliss TV, Collingridge GL. A synaptic model of memory: longterm potentiation in the hippocampus. Nature. 1993;361:31-39.

18 Tsien JZ, Huerta PT, Tonegawa S. The essential role of hippocampal CA1 NMDA receptor-dependent synaptic plasticity in spatial memory. Cell. 1996;87:1327-1338.

19 Tang YP, Shimizu E, Dube GR, Rampon C, Kerchner GA, Zhuo $\mathrm{M}$, et al. Genetic enhancement of learning and memory in mice. Nature. 1999;401:63-69.

20 Malleret G, Haditsch U, Genoux D, Jones MW, Bliss TV, Vanhoose AM, et al. Inducible and reversible enhancement of learning, memory, and long-term potentiation by genetic inhibition of calcineurin. Cell. 2001;104:675-686.

21 Gerlai R, Henderson JT, Roder JC, Jia Z. Multiple behavioral anomalies in GluR2 mutant mice exhibiting enhanced LTP. Behav Brain Res. 1998;95:37-45.

22 Migaud M, Charlesworth P, Dempster M, Webster LC, Watabe AM, Makhinson M, et al. Enhanced long-term potentiation and impaired learning in mice with mutant postsynaptic density-95 protein. Nature. 1998;396:433-439.

23 Uetani N, Kato K, Ogura H, Mizuno K, Kawano K, Mikoshiba $\mathrm{K}$, et al. Impaired learning with enhanced hippocampal longterm potentiation in $\mathrm{PTP} \delta$-deficient mice. Embo J. 2000;19: 2775-2785.

24 Moser EI, Krobert KA, Moser MB, Morris RG. Impaired spatial learning after saturation of long-term potentiation. Science. 1998;281:2038-2042.

25 Brun VH, Ytterbo K, Morris RG, Moser MB, Moser EI. Retrograde amnesia for spatial memory induced by NMDA receptor-mediated long-term potentiation. J Neurosci. 2001; 21:356-362.

26 Nelson BR, Claes K, Todd V, Chaverra M, Lefcort F. NELL2 promotes motor and sensory neuron differentiation and stimulates mitogenesis in DRG in vivo. Dev Biol. 2004;270:322-335. 